\title{
Simulation of different age distributions for the analysis of the aging curve of a population of "S. cerevisiae".
}

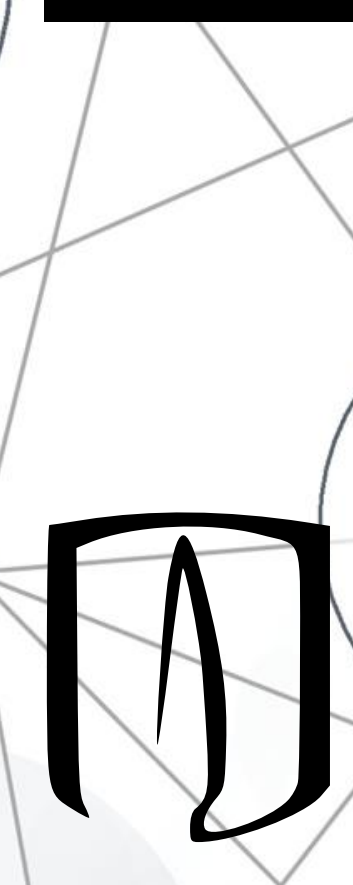

Ivonne Paola Rojas Martínez ${ }^{1,2}$ - iprojasm@correo.udistrital.edu.co David Camilo Durán Chaparro1-da-duran@uniandes.edu.co Juan Manuel Pedraza Leal ${ }^{1}$ - jmpedraza@uniandes.edu.co 


\section{ABSTRACT}

Newly developed microfluidic devices ("Mother Machines") have improved data gathering for the study of aging in unicellular models, and thereby the understanding of this process. Each device has different features that cause them to have certain advantages or disadvantages. At the University of the Andes a new microfluidic device was developed that uses the Slipstreaming effect to trap the cells. This has the advantage of not using mechanical pressure to trap the cells, but as it starts with a mixed age population it does not guarantee that the cells studied are virgin.

One of the basic outputs in these studies is the aging curve, which shows how the fraction of viable cells varies with respect to time. From this it can be deduced how fast or slow the population ages. For devices where it is not possible to work with virgin cells the age distribution is assumed, but changes in this distribution could affect the analysis of the data.

Therefore, the present work seeks to carry out a series of simulations to find the different age distributions that could be present and determine the corresponding changes in the aging curve. We propose two population growth models, synchronous and asynchronous. For each model we will start with the possible age distributions and determine the various curves that can be obtained and then compare these computational results with the experimental data to propose a better interpretation of the data obtained from Mother Machine devices. 


\section{INTRODUCTION}

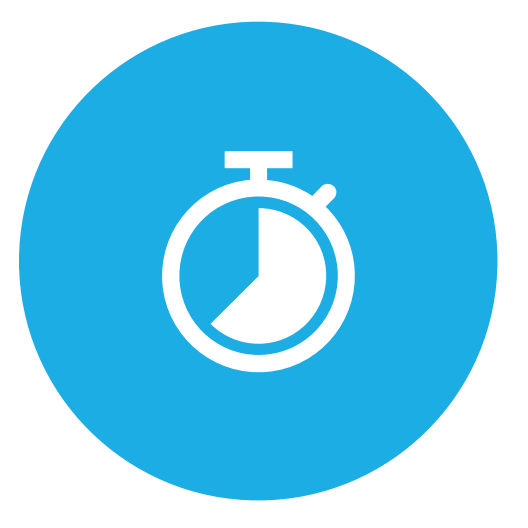

AGING

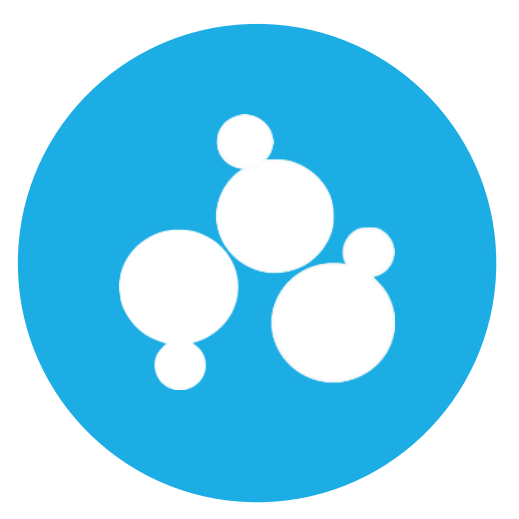

YEAST CELLS

It is a model organism because it is a very simple eukaryotic cell and has replicative aging

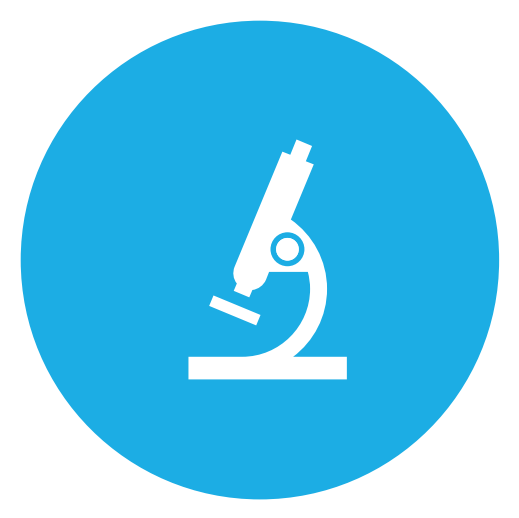

MICROFLUIDIC DEVICES

Our devices work via a laminar flow and which detaches the daughter cells from the mother cells$$
\text { (alls }
$$

Changes in the function of the cells over time which can trigger different kinds of diseases 


\section{SYSTEMS BIOLOGY OF CELLS AGING}

With the help of computational modeling and quantitative analysis of complex biological systems, it takes a different approach to research, providing another point of view to the large number of experimental results that are obtained, giving a map or a route of the different networks of aging (Song et al., 2018)

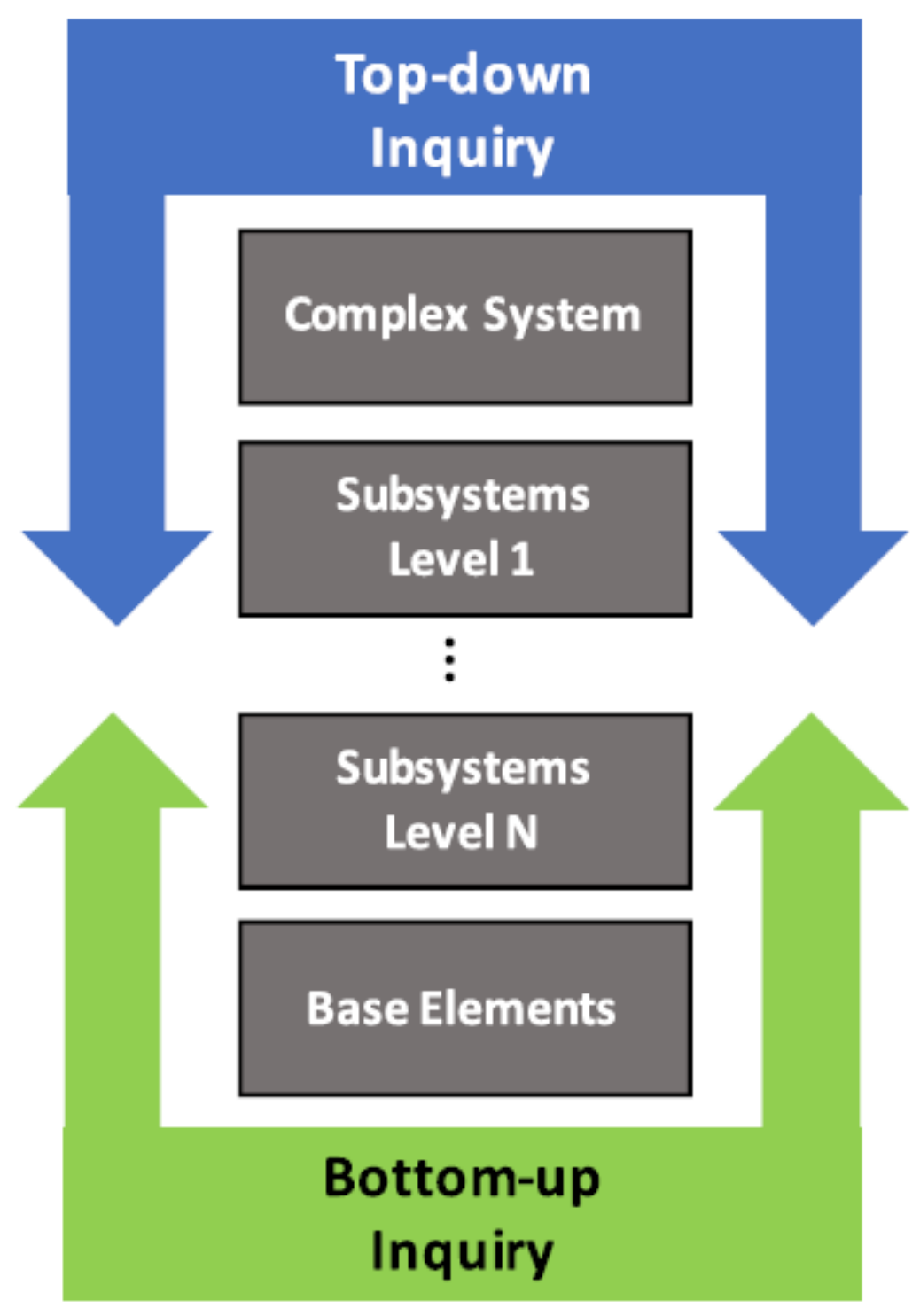

Outline of the two ways by which aging can be analyzed. Image taken from : The Systems Biology of Single-Cell Aging 


\section{REPLICATIVE AGING}

According to Steinkraus ef $a l,(2008)$ the replicative aging can be defined as "the cumulative number of mitotic divisions a cell can undergo" (p.31).

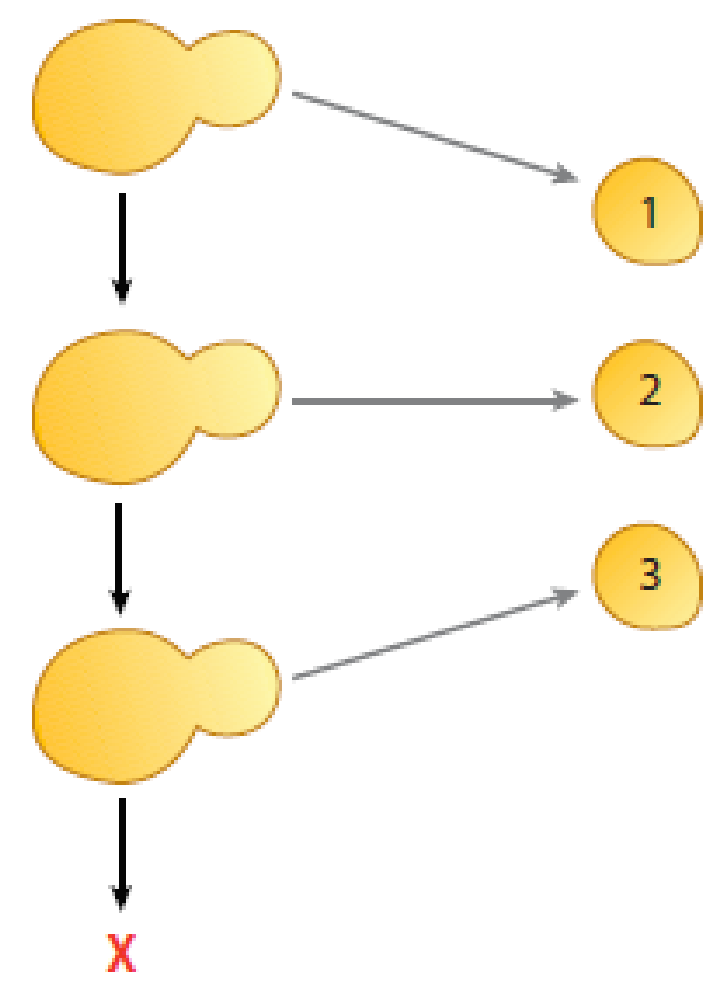

Chronological life span $=$ days viable in

postreplicative state

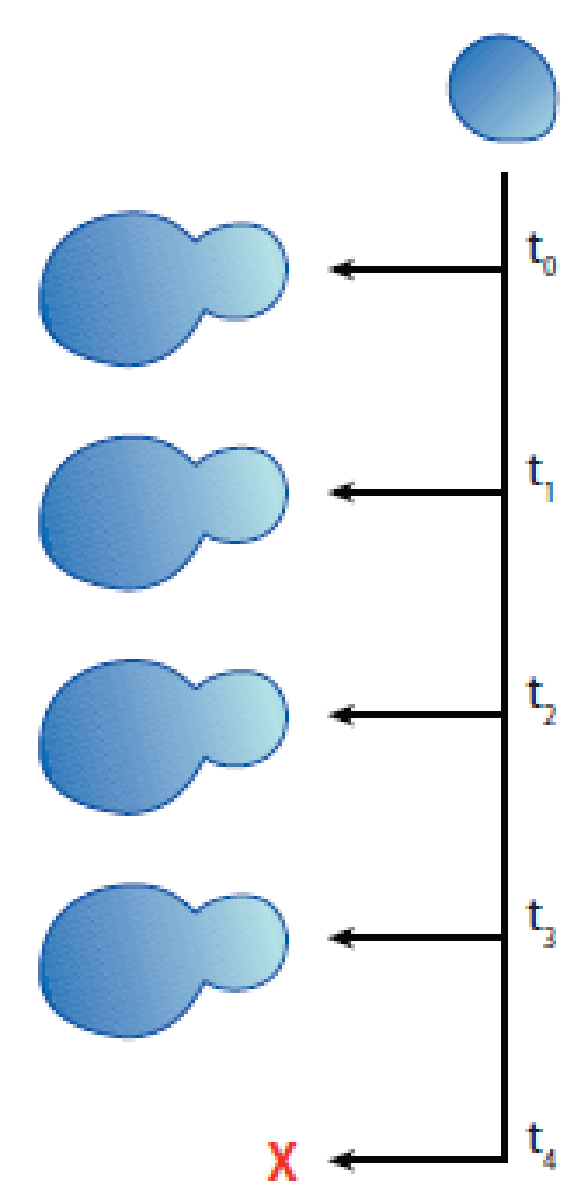




\section{AGING CURVE}

Simulation

RLS

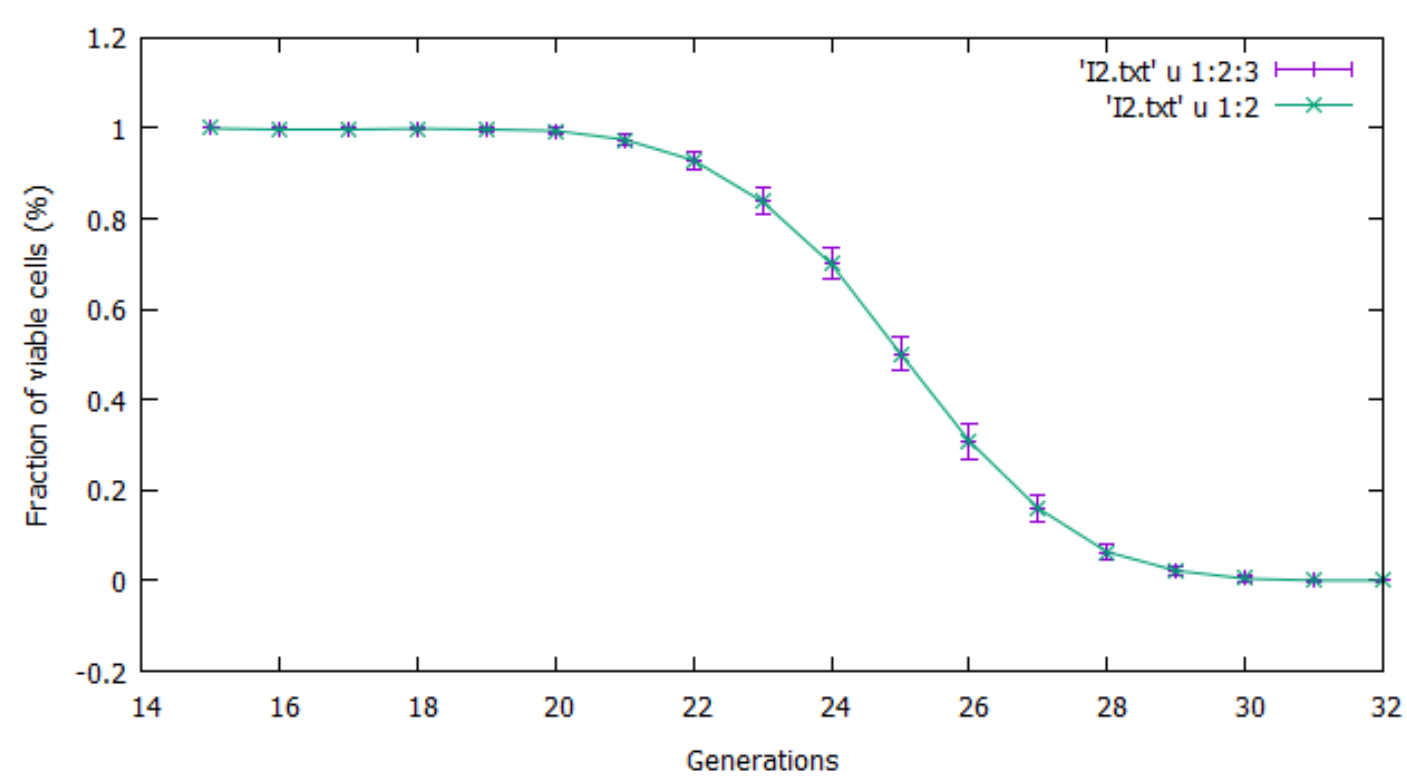

The replicative life span is simulated using parameters obtained from a population of cells.

\section{Experimental}

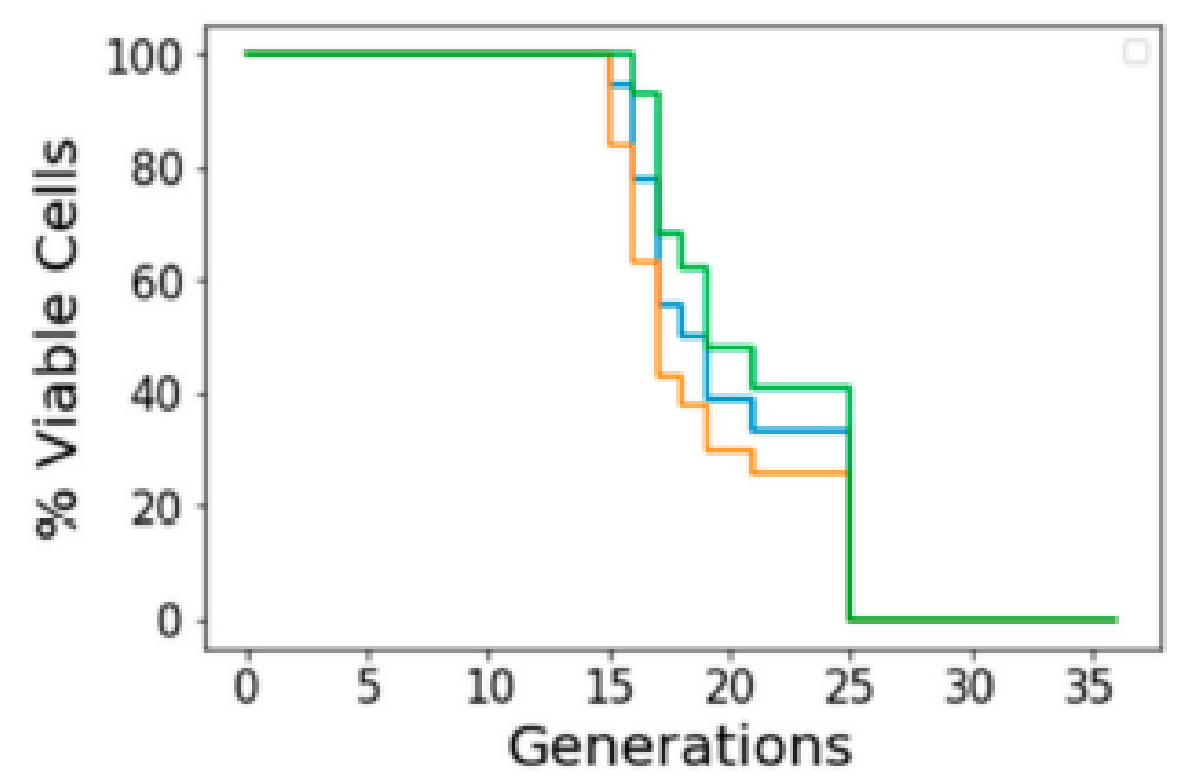

Experimental aging curve . Image taken from: Slipstreaming Mother Machine: A Microfluidic Device for Single-Cell Dynamic Imaging of Yeas, Durán et al. (2021) 


\section{SLIPSTREAMING MOTHER MACHINE}

David C. Durán ${ }^{1, *(\mathbb{C})}$, César A. Hernández ${ }^{2} \mathbb{C}$, Elizabeth Suesca ${ }^{1}$, Rubén Acevedo ${ }^{1}$, Ivón M. Acosta ${ }^{1,3}$

Diana A. Forero ${ }^{1,3}$, Francisco E. Rozo ${ }^{1,3}$ and Juan M. Pedraza ${ }^{1, *(B)}$

1 Laboratorio de Biofísica, Departamento de Física, Universidad de los Andes, Bogotá 111711, Colombia; e.suesca87@uniandes.edu.co (E.S.); rl.acevedo10@uniandes.edu.co (R.A.)

imacostah@corneo.udistrital.edu.co (I.M.A.); daforerog@correo.udistrital.edu.co (D.A.F.)

ferozob@correo.udistrital.edu.co (F.E.R.)

2 Centro de Microelectrónica, Departamento de Ingeniería_Eléctrica v Electrónica, Universidad de los Andes CMUA, Bogotá 111711, Colombia; ca.hernandez11@u

Proyecto Curricular Licenciatura en Física, Facultad de José de Caldas, Bogotá 110311, Colombia

* Correspondence: da-duran $\varrho$ uniandes.edu.co (D.C.D.) Tel.: +57-1-3394949 (ext. 5179 (COL)) (J.M.P.)

Abstract: The yeast Saccharomyces cerevisiae is one of aging and other phenomena such as division st studied with the use of microfluidic devices to keep However. all of the existing devices trav cells mech

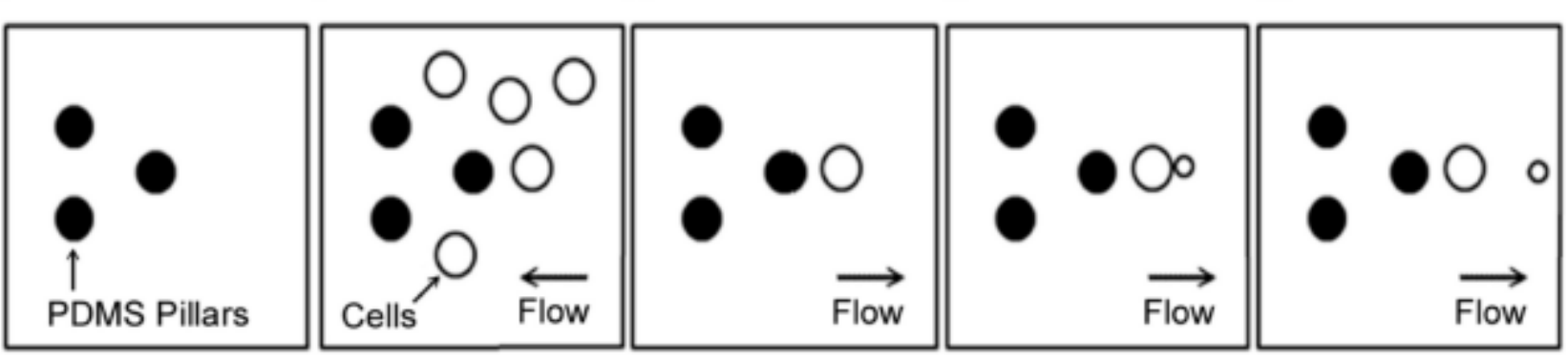




\section{HOW COULD THE AGE DISTRIBUTION AFFECT THE}

AGING CURVE?

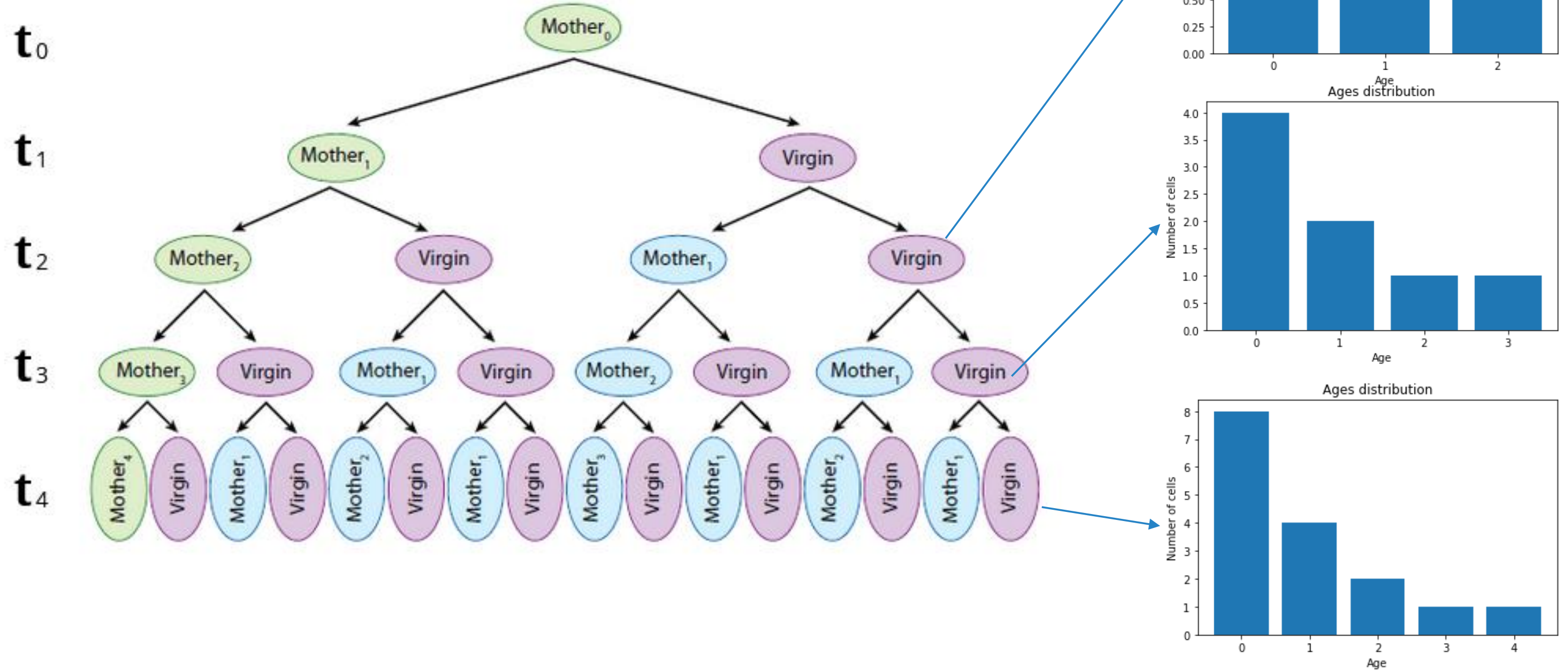




\section{RESULTS}

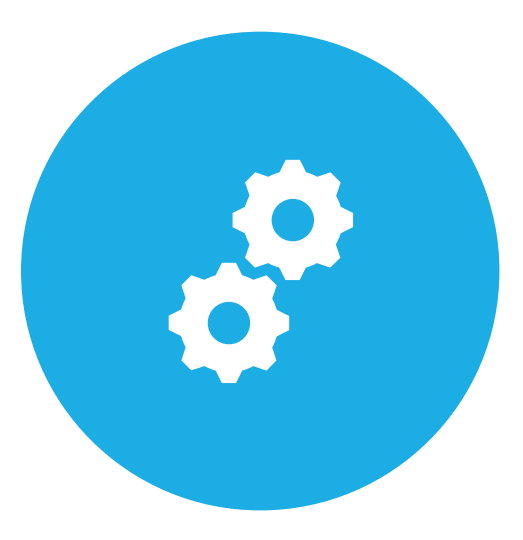

MODELS

Implementation of two models developed in the Python programming language
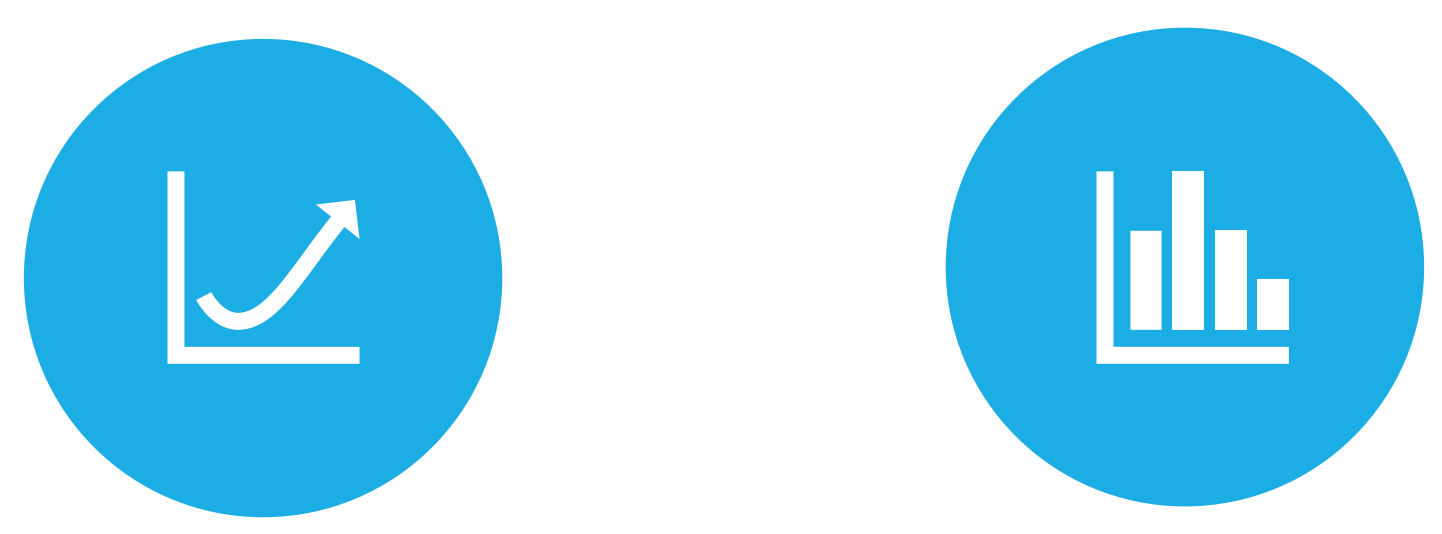

GROWTH CURVE

A code that simulates the exponential and stationary phases of yeast population growth.

\section{AGE DISTRIBUTION}

A code that simulates the distributions of ages, according to the division times, as a function of time. 


\section{SYNCHRONOUS MODEL}

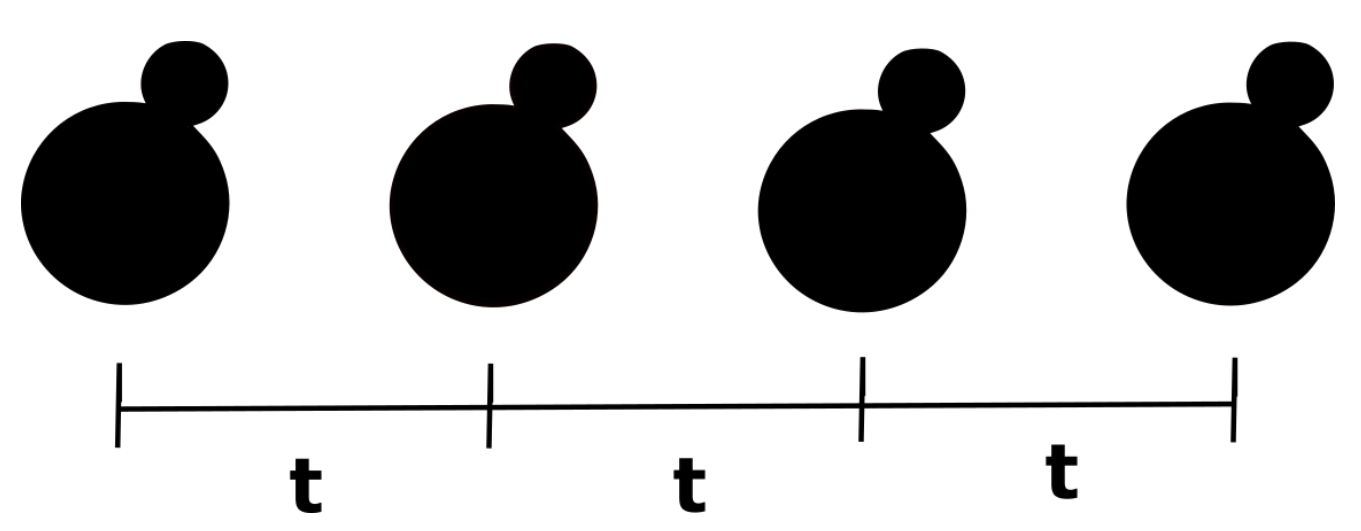

- The count begins with one single cell

-All the cells are replicated at the same time

- The age is defined as the number of daughter cells that each cell has had

- In this model the death times are deterministic

\section{ASYNCHRONOUS MODEL}
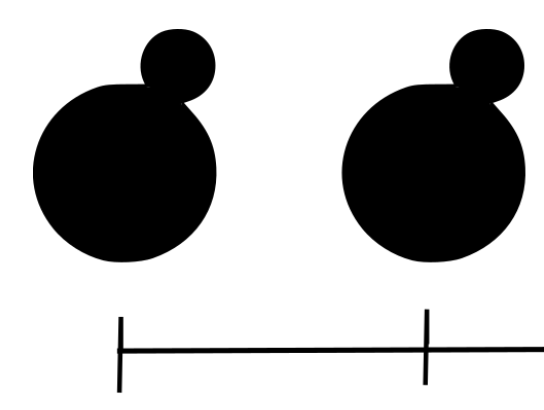

$\mathbf{t}_{1}$
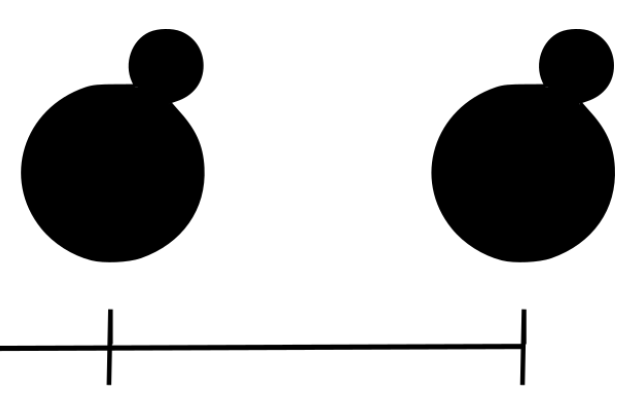

$\mathbf{t}_{\mathbf{0}}$

$\mathbf{t}_{2}$

$\mathbf{t}_{3}$

- This model includes the fact that cells do not divide at the same time

- We obtained the distribution of replication times from experimental data by fitting a normal distribution

- A replication time from that distribution it is assigned at each division

- We ignored mother-daughter correlations in division times 


\section{SYNCHRONOUS WITH CONSTANT REPLICATION}

TIMES
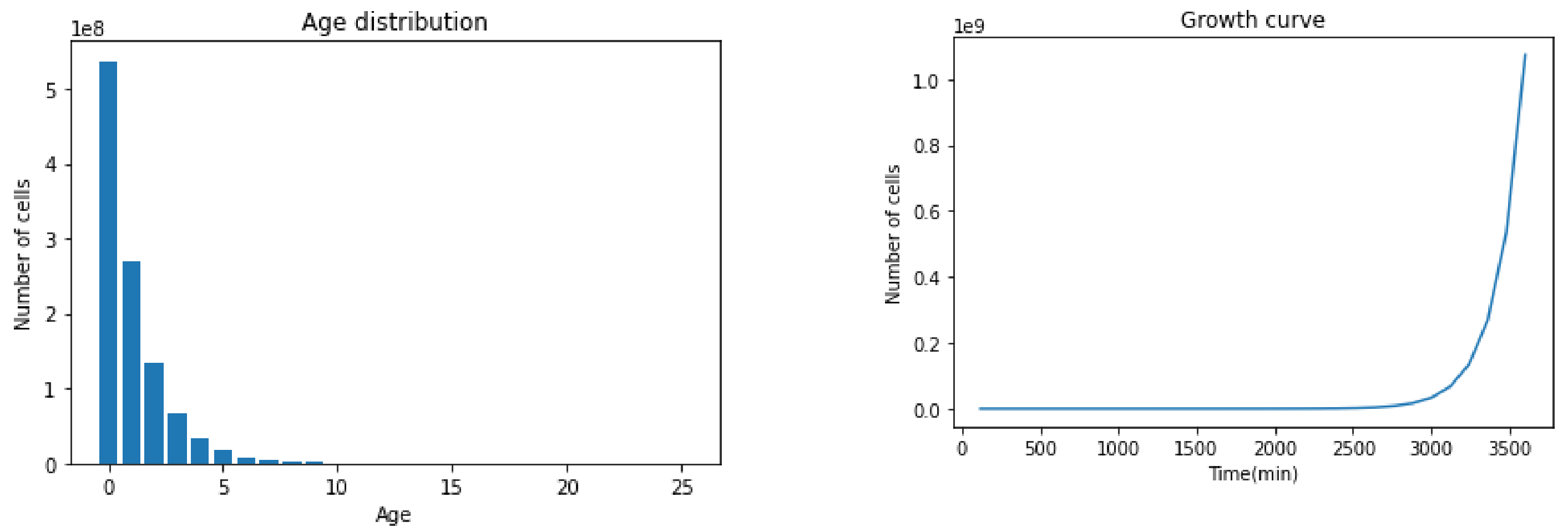

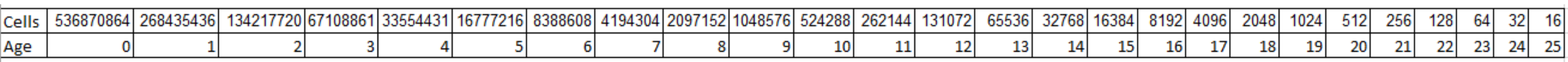

In this case we suppose that the cells died at the age of 25 


\section{ASYNCHRONOUS WITH INCREASING REPLICATION TIMES}
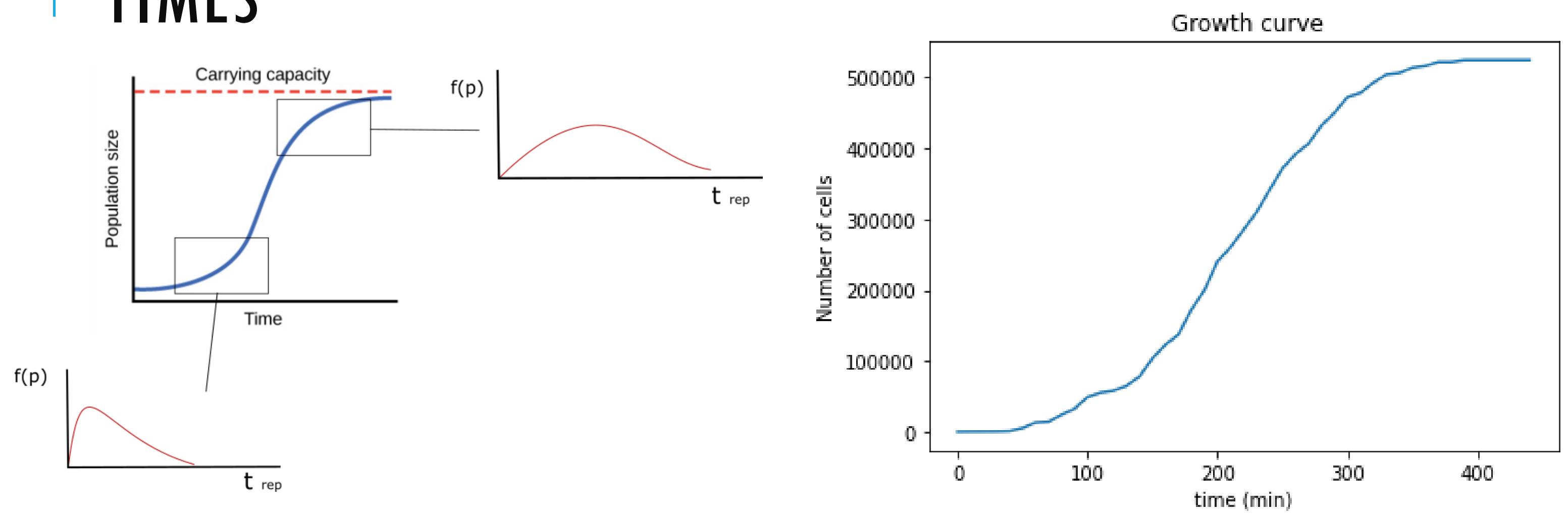

\begin{tabular}{|c|c|c|c|c|c|c|c|c|c|c|c|c|c|c|c|c|c|c|c|c|c|c|c|c|c|c|}
\hline & \multirow{2}{*}{\begin{tabular}{|l|r|} 
Cells & 262144 \\
Age & 0
\end{tabular}} & 131072 & 65536 & 32768 & 16384 & 8192 & 4096 & 2048 & 1024 & 512 & 256 & 128 & 64 & 32 & 16 & 8 & 4 & 2 & 1 & 1 & 0 & 0 & 0 & 0 & & 0 \\
\hline & & & & & & & & & & 9 & 10 & 11 & 12 & 13 & 14 & 15 & 16 & 17 & 18 & 19 & 20 & 21 & 22 & 23 & 24 & \\
\hline
\end{tabular}




\section{COMPARING SIMULATED RLS CURVES}

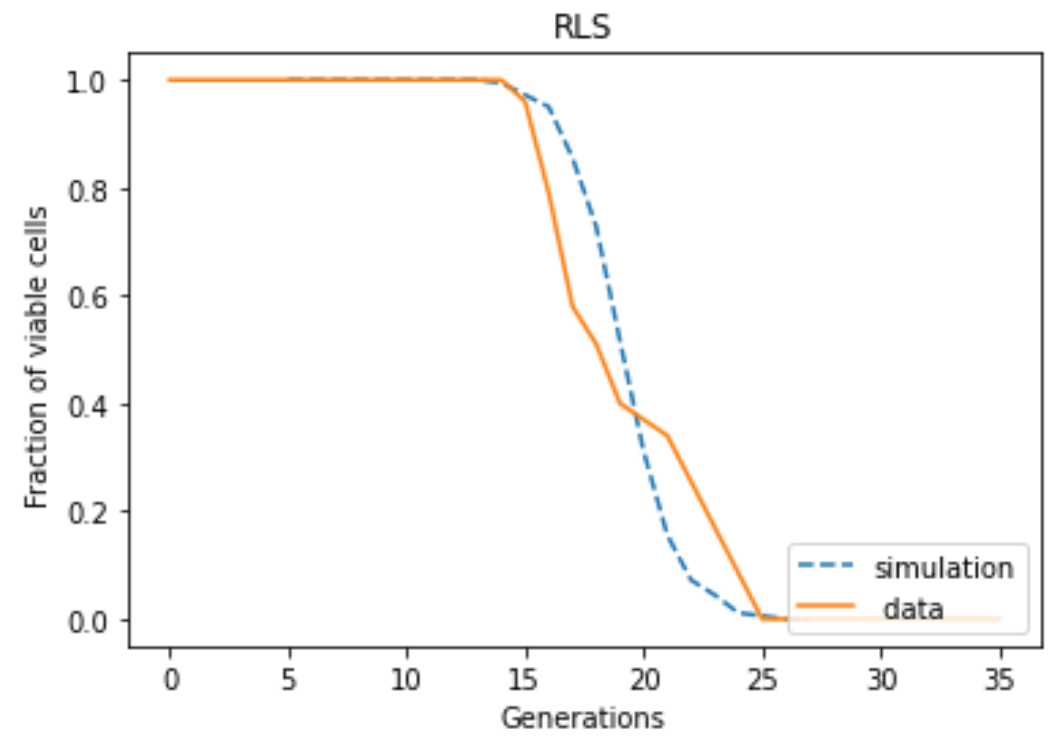

$$
\begin{aligned}
& \text { Virgin, } g=0 \\
& \text { medianRLS=19,3 }
\end{aligned}
$$

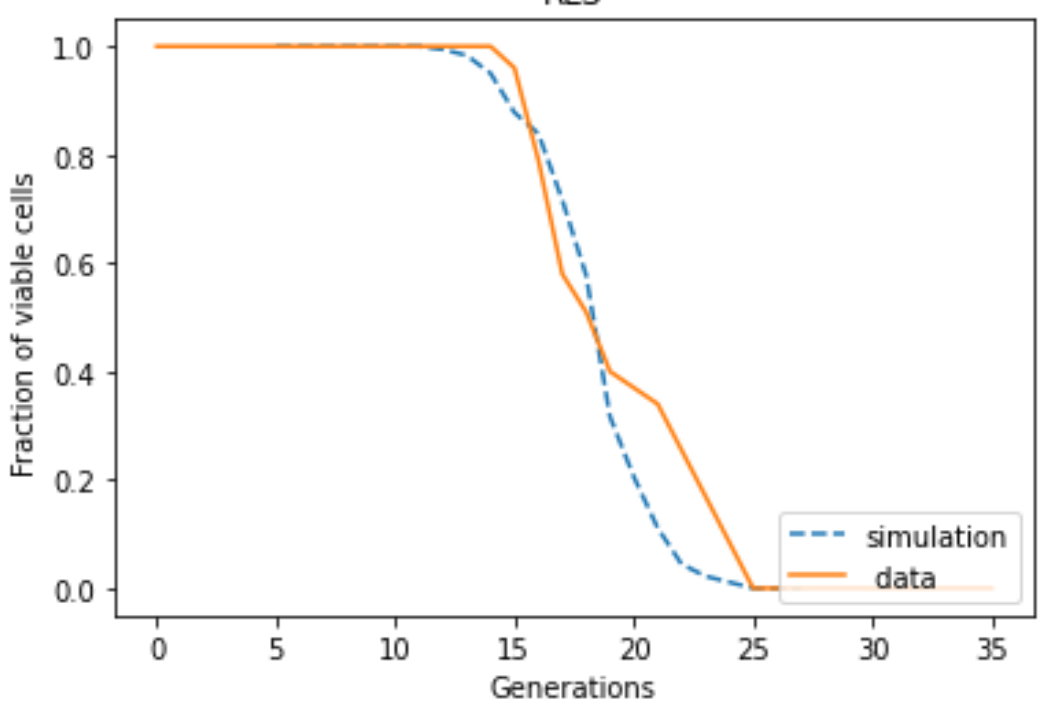

$$
g=20
$$

medianRLS $=18,1$

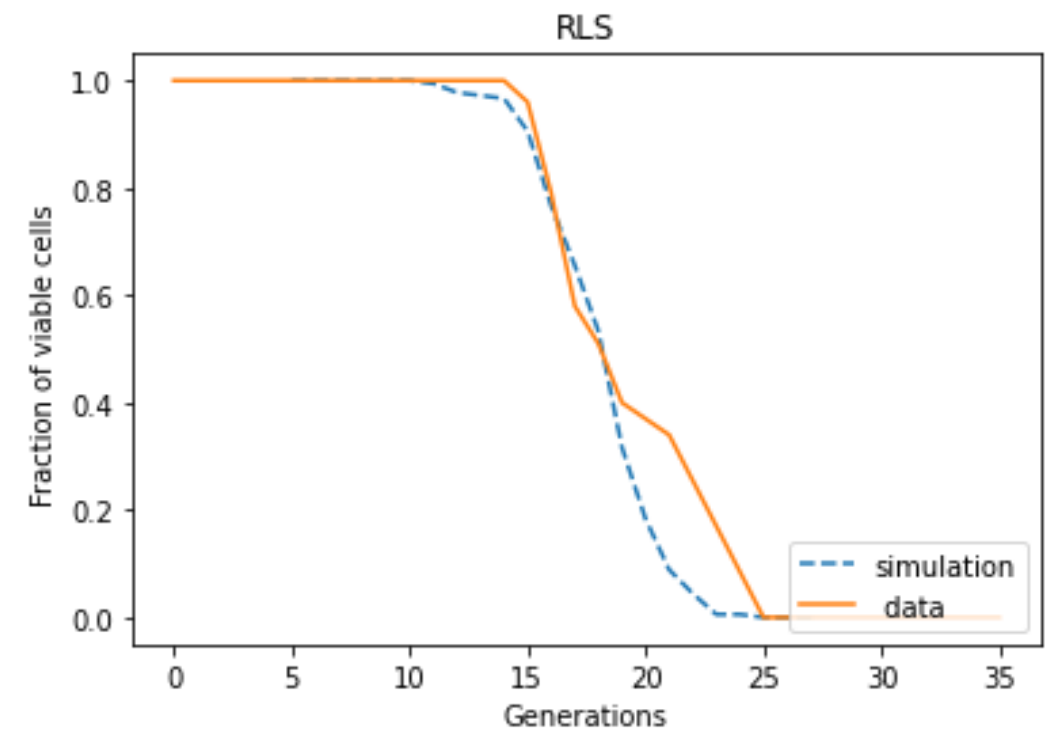

$g=10$

medianRLS $=18.3$

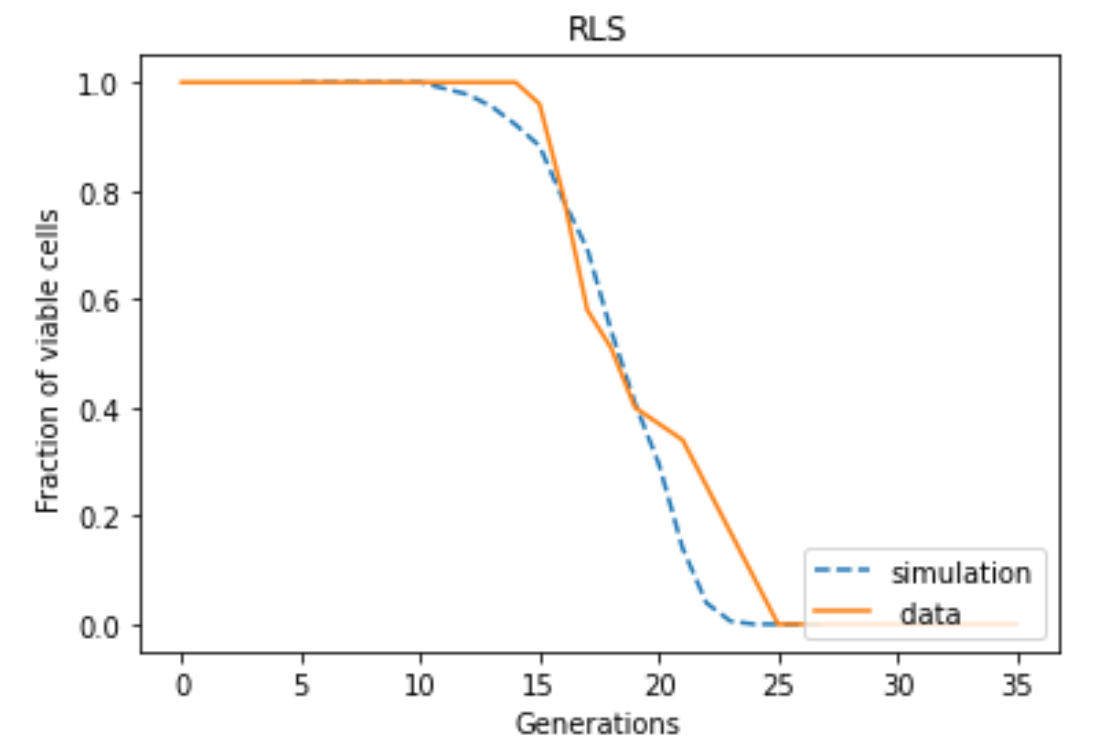

$g=30$

medianRLS=18,2

We compare the RLS resulting from age distributions at different generations $(0,10,20,30)$

experimental data taken from: Durán et al. (2021) 


\section{DISCUSSION}

$>$ In the first approximation of the synchronous model, it cannot simulate the logistic behavior of the growth of a yeast cell population.

$>$ Now, the being death is determined at a certain age, we plan to determine a distribution of death times to be added to the simulation.

We want to adjust the asynchronous model with the experimental data to adjust the time at which the stationary phase is reached and thus improve the simulation.

By having different age distributions in different generations, the RLS curves change, but they fit the experimental data. 


\section{CONCLUSIONS}

We were able to determine an age distribution for the two models.

The initial model was adjusted to include death and fit the replicative times to more closely resemble the growth behavior of a yeast cell population.

We have a model that simulates the growth of the population and gives the time in which a certain distribution may occur.

When considering a possible distribution of initial ages, in a first analysis, the RLS curve is affected, causing it to give a lower RLS value than expected. 


\section{ACKNOWLEDGEMENTS}

The authors would like to thank the Biophysics Group at Universidad de los Andes for useful discussions of work, as well as Steven Rozo for providing the data on cell replication times.

I thank the Universidad Distrital and the agreement with the Universidad de los Andes that allowed me to do my internship at this university.
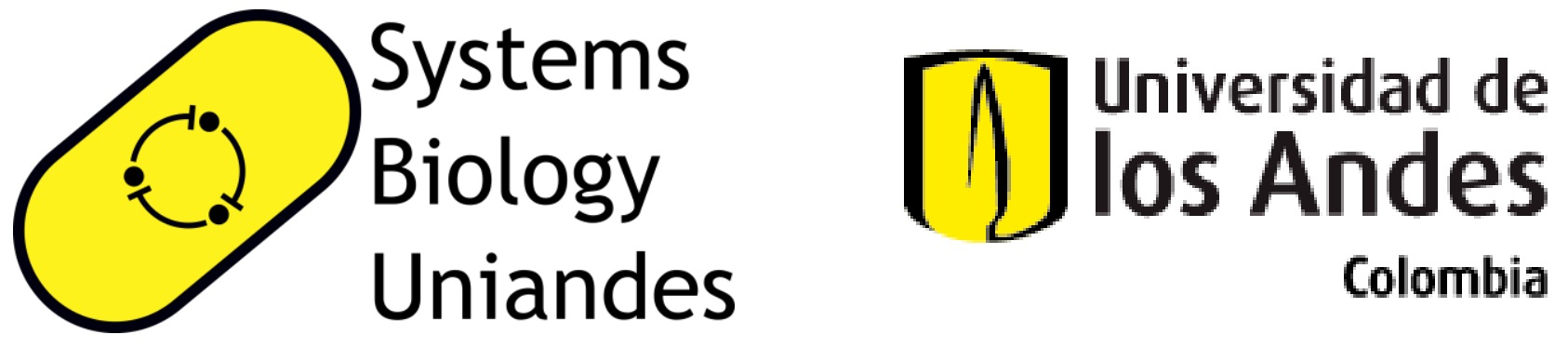


\section{BIBLIOGRAPHY}

$>$ Durán, D. C., Hernández, C. A., Suesca, E., Acevedo, R., Acosta, I. M., Forero, D. A., Rozo, F. E., \& Pedraza, J. M. (2021). Slipstreaming mother machine: A microfluidic device for single-cell dynamic imaging of yeast. Micromachines, 12(1), 1-11. https://doi.org/10.3390/mi12010004

$>$ Song, R., Sarnoski, E. A., \& Acar, M. (2018). The Systems Biology of Single-Cell Aging. IScience, 7, 154169. https://doi.org/10.1016/j.isci.2018.08.023

$>$ Steinkraus, K. A., Kaeberlein, M., \& Kennedy, B. K. (2008). Replicative aging in yeast: The means to the end. Annual Review of Cell and Developmental Biology, 24, 29-54.

https://doi.org/10.1146/annurev.cellbio.23.090506.123509 